\title{
Agroindústrias rurais familiares (ARFs) como estratégia de reprodução socioeconômica da agricultura familiar nos municípios de Santo Augusto $e$ Campo Novo - RS
}

\author{
Rosani Marisa Spanevello \\ Universidade Federal de Santa Maria - Palmeira das Missões - Rio Grande do Sul \\ - Brasil

\section{Luana Cristina Duarte} \\ Universidade Federal de Santa Maria - Palmeira das Missões - Rio Grande do Sul \\ - Brasil

\section{Catia Letícia Corrêa Schneider} \\ Universidade Federal de Santa Maria - Palmeira das Missões - Rio Grande do Sul \\ - Brasil

\section{Sinara Pizzi Martins} \\ Universidade Federal de Santa Maria - Palmeira das Missões - Rio Grande do Sul \\ - Brasil
}

\section{Resumo}

As agroindústrias rurais familiares (ARFs) têm se tornado uma importante estratégia de reprodução socioeconômica na agricultura familiar. Assim, o objetivo deste artigo é analisar - em um caso específico - a importância dos processos de agroindustrialização nas propriedades rurais que transformam parcialmente/totalmente a matéria-prima, buscando responder: qual é a importância dos processos de agroindustrialização nas propriedades rurais? Como as ARFs promovem a reprodução socioeconômica da unidade familiar? A revisão bibliográfica parte das discussões em torno da reprodução socioeconômica da agricultura familiar, das ARFs, aqui tidas como uma estratégia de reprodução das famílias e as contribuições que estas trazem ao contexto de desenvolvimento rural. O contexto empírico de pesquisa envolveu os municípios de Santo Augusto e Campo Novo/RS no período de dezembro de 2017. A metodologia consistiu em um estudo de caso com quatro ARFs definidas como agroindústria $\mathrm{A}$ (processadora de melado), agroindústria $\mathrm{B}$ (de embutidos), agroindústria $C$ (de mandioca) e agroindústria $D$ (de panificados). Os resultados demonstraram que as ARFs surgem como novas práticas de desenvolvimento rural, na medida em que garantem a permanência das famílias no campo, principalmente jovens e 
mulheres. É utilizada pelos agricultores como uma estratégia de renda complementar, agregação de valor aos produtos e diversificação por meio de atividades pluriativas, na busca por maior qualidade de vida da família. As ARFs também contribuem diretamente com o desenvolvimento socioeconômico local, preservando a cultura e as tradições, uma vez que seus produtos são comercializados no município, como em supermercados, escolas, feiras, entre outros.

Palavras-chave: Agroindustrialização. Desenvolvimento Local. Estratégias. Agregação de Valor.

\section{Rural family agro-industries (RFAs) as a strategy for socioeconomic reproduction of family farming in the municipalities of Santo Augusto and Campo Novo - RS}

Abstract

Rural family agro-industries (RFAs) have become an important strategy for socioeconomic reproduction in family farming. In this way, the aim of this article is to analyze - in a specific case - the importance of agro-industrialization processes in rural properties that partially or totally transform the raw material. And then, answer these questions: What is the importance of agro-industrialization processes in rural properties? How do RFAs promote socioeconomic reproduction of the family unit? The literature review is based on the discussions about the socioeconomic reproduction of family farming, the RFAs, here considered as a reproduction strategy of the families, and the contributions they bring to the context of rural development. The empirical research context involved the municipalities of Santo Augusto and Campo Novo/RS in the period of December 2017. The methodology consisted of a case study with four ARFs defined as agro-industry A (molasses processing), agro-industry $B$ (processed meat), agro-industry $C$ (cassava) and agro-industry D (bakery products). The results indicated that the ARFs appear as new practices of rural development, since they ensure the permanence of families in the field, mainly young people and women. Also, it is used by farmers as a complementary income strategy, adding value to the products and diversifying through pluriactive tasks, aiming a higher quality of family life. ARFs contribute directly to local socioeconomic development, preserving culture and traditions, since their products are sold in the municipality, as in supermarkets, schools, fairs, among others.

Keywords: Agro-industrialization. Local Development. Strategies. Adding Value.

\section{Agroindustrias rurales familiares (ARFs) como estrategia de reproducción socioeconómica de la agricultura familiar en los municipios de Santo Augusto y Campo Novo - RS}

\section{Resumen}

Las agroindustrias rurales familiares (ARFs) se han vuelto una importante estrategia de reproducción socioeconómica en la agricultura familiar. El objetivo de este artículo, por lo tanto, es analizar -en un caso específico- la importancia de los procesos de agroindustrialización en las propiedades rurales que transforman parcialmente/totalmente la materia-prima, buscando responder: ¿Cuál es la importancia de los procesos de agroindustrialización en las propiedades rurales? ¿Cómo las ARFs promueven la reproducción socioeconómica de la unidad familiar? La revisión bibliográfica parte de las discusiones en torno de la reproducción socioeconómica de la agricultura familiar, de las ARFs, que aquí se consideran una estrategia de reproducción de las familias y los aportes que estas traen al contexto de desarrollo rural. El contexto empírico de investigación incluyó los municipios de Santo Augusto y Campo Novo/RS, durante el período de diciembre de 2017. La metodología consistió en un estudio de caso con cuatro ARFs, definidas como agroindustria A (procesadora de melado), agroindustria B (de embutidos), agroindustria C (de mandioca) y 
agroindustria $\mathrm{D}$ (de panificados). Los resultados mostraron que las $A R F s$ surgen como nuevas prácticas de desarrollo rural, ya que aseguran la permanencia de las familias en el campo, principalmente jóvenes y mujeres. Los agricultores la utilizan como una estrategia para complementar sus ingresos, agregar valor a los productos y diversificarlos por medio de actividades pluriativas en la búsqueda por una mejor calidad de vida de la familia. Las ARFs también contribuyen directamente con el desarrollo socioeconómico local, preservando la cultura y las tradiciones, ya que sus productos se comercializan en el municipio, en supermercados, escuelas, ferias, entre otros.

Palabras clave: Agroindustrialización. Desarrollo Local. Estrategias. Agregado de Valor.

\section{Introdução}

Os processos de modernização e mercantilização da agricultura brasileira, sobretudo, a partir dos anos de 1960, acabaram produzindo uma nova organização do meio rural e das suas particularidades. Por um lado, incentivou a produção em larga escala, o progresso tecnológico e o crescimento da economia. Por outro, esse processo foi extremamente seletivo, afetando pequenos e médios agricultores rurais, contribuindo com o êxodo rural (PLEIN, 2006; WANDERLEY, 2014).

Entretanto, o desenvolvimento histórico demonstrou que a agricultura familiar ainda continuou crescente, mesmo em contextos de instabilidade, como os da mercantilização e da modernização da agricultura brasileira. Segundo Plein (2010, p. 98), as formas familiares de produção demonstraram resistência inclusive "na estrutura agrária nos países onde o modo de produção capitalista mais se desenvolveu principalmente no período pós-guerra (1945-1973)" pela produção de alimentos. Portanto, a produção agrícola familiar se mostrou capaz de se reproduzir e se manter ao longo do tempo, adaptando-se ao ambiente na qual foi sendo inserida (JEAN, 1994).

É a partir destas discussões - de resistência dos agricultores frente aos contextos de instabilidade - que surgem muitos estudos no meio acadêmico enfatizando as diferentes estratégias de reprodução socioeconômica da agricultura familiar (SCHNEIDER; NIEDERLE, 2010). Segundo Schneider (2009), as estratégias podem ser definidas como o resultado das decisões e escolhas dos agricultores decorrentes das pressões externas ou internas à família, que podem ser sociais, culturais, econômicas, espaciais, entre outras.

As agroindústrias rurais familiares (ARFs) estão entre estas estratégias de reprodução socioeconômica da agricultura familiar (GNOATTO et al., 2004; GAZOLLA; PELEGRINI, 2008). As ARFs têm contribuído para a geração de emprego e renda, servindo de estímulo à permanência das famílias no campo, principalmente, de jovens e mulheres, atribuindo maior qualidade de vida aos agricultores e auxiliando na redução do êxodo rural (FERNANDES; ENGEL, 2016; AGNE; WAQUIL, 2011; BORTOLUZZI, 2013).

Além disso, o processo de agroindustrialização tem contribuído com a agregação de valor de produtos locais, ressaltando a importância da agricultura familiar como produtora de alimentos, o qual procura valorizar aspectos tradicionais, culturais e de hábitos alimentares, bem como, contribui com a preservação ambiental (já que suas bases produtivas são mais sustentáveis) e com a crescente relevância das atividades pluriativas (agrícolas e não agrícolas) como alternativa de reprodução 
socioeconômica familiar (ORSOLIN, 2006; BORTOLUZZI, 2013; FERNANDES; ENGEL, 2016).

Segundo informações da Empresa de Assistência Técnica e Extensão Rural do Governo do Rio Grande do Sul (EMATER/RS, 2019), a atividade de agroindustrialização no estado gaúcho vem se tornando cada vez mais expressiva. De acordo com o Censo Agropecuário de 2006, o número de estabelecimentos agropecuários que realizava essa atividade era de 82.220. Destes, 30.255 afirmaram possuir renda com a atividade desenvolvida. Ainda segundo a EMATER/RS (2019), no ano de 2007, o valor bruto das atividades agropecuárias do estado era de aproximadamente $\mathrm{R} \$ 2,3$ bilhões, representando aproximadamente $76,67 \%$ da estimativa brasileira neste mesmo período.

Atualmente, o número de agroindústrias familiares divulgado no último relatório da Secretaria do Desenvolvimento Rural, Pesca e Cooperativismo (SDR), de outubro de 2018, é expressivo, sendo este representado por 4.429 agroindústrias. Esse número caracteriza somente as agroindústrias que são regularizadas, possuem selo de certificação e estão incluídas no Programa Estadual de Agroindústria Familiar (PEAF) (SDR, 2018).

Diante desse contexto, este estudo tem a finalidade de analisar - em um caso específico - a importância dos processos de agroindustrialização nas propriedades rurais que transformam parcialmente/totalmente a matéria-prima, respondendo as seguintes questões norteadoras do trabalho: Qual é a importância dos processos de agroindustrialização nas propriedades rurais? Como as agroindústrias rurais familiares promovem a reprodução socioeconômica da unidade familiar?

O contexto empírico envolveu os municípios de Santo Augusto e Campo Novo no estado do Rio Grande do Sul. A pesquisa de campo foi realizada em dezembro de 2017. A metodologia consistiu de um estudo de caso por meio de entrevistas com os gestores de quatro agroindústrias rurais familiares, definidas como agroindústria $A$ (processadora de melado), agroindústria B (de embutidos), agroindústria C (de mandioca) e agroindústria $D$ (de panificados). As entrevistas foram realizadas por meio da aplicação de questionários mistos (questões abertas e fechadas) como forma de obtenção e coleta de informações.

O presente artigo está organizado em cinco seções, contando a partir desta introdução. A segunda é composta por uma revisão bibliográfica com ênfase nas discussões em torno da reprodução socioeconômica da agricultura familiar e das definições e contribuições das agroindústrias rurais familiares, aqui tidas como uma estratégia de reprodução socioeconômica das famílias. A terceira seção abrange os procedimentos metodológicos de pesquisa e a quarta, os resultados e discussões. Por fim, a quinta seção apresenta as considerações finais.

\section{Reprodução socioeconômica da agricultura familiar}

O contexto histórico recente da agricultura brasileira demonstrou que os processos de modernização e mercantilização nos quais ela está baseada, sobretudo, a partir dos anos 1960, produziram "uma notável diversidade e diferenciação social" no meio rural (NIEDERLE; ESCHER; CONTERATO, 2014, p. 205). Parte-se da noção de um rural homogêneo e agrícola (como era visto antes da modernização) para um rural moderno, complexo e dinâmico, constituído por uma heterogeneidade de 
atores, formas de organização de trabalho e meios de subsistência (NIEDERLE; ESCHER; CONTERATO 2014; WANDERLEY, 2014).

Nesse enredo, sociedades rurais tradicionais, tais como o campesinato, sofreram profundas transformações socioeconômicas. Segundo Wanderley (2000), essas transformações se refletiram especialmente nas formas de produção e organização dos camponeses e suas relações com o mercado, ao qual se tornaram mais integradas, principalmente com mercados não locais.

Desse processo de integração aos mercados, surge o conceito de mercantilização. A mercantilização se caracteriza pela relação entre o agricultor e o mercado, que comercializa o excedente de sua produção, bem como, adquire os fatores de produção, como sementes, adubos, fertilizantes, tecnologias, entre outros. Portanto, para o autor, o mercado passa a conduzir o sistema produtivo da agricultura e os agricultores se tornam mais dependentes desse processo (PLEIN, 2003).

O resultado da crescente dependência do mercado e externalização dos fatores de produção levam cada vez mais a noção de uma agricultura mercantilizada, que de acordo com Ploeg (1992, p. 169 - 172), impõem em transformações significativas das unidades produtivas, que

[... ] no sólo afecta las actividades de producción sino que resulta también en una transformación completa del proceso de reproducción (...). De este modo las relaciones mercantiles penetran hasta el centro del proceso productivo y comienzan a mercantilizar el proceso de trabajo mismo.

Atualmente, além da dependência dos mercados, os agricultores enfrentam inúmeros contextos de contingências e instabilidades. Entre os fatores que condicionam estes contextos, estão os citados por Silva e Hespanhol (2016, p. 407) como: "dificuldades na produção e comercialização; dificuldades de acesso às políticas públicas voltadas para o grupo; carência de maquinários e mão de obra; precarização dos acessos/estradas [...]", entre outros.

Nesse sentido, surgem diferentes estratégias de reprodução socioeconômica da agricultura familiar como alternativa aos agricultores de se manterem ou se adaptarem às transformações a eles impostas. As estratégias de reprodução socioeconômicas são definidas como o resultado das ações, decisões e escolhas das unidades familiares frente a contextos de pressões externas ou internas à família, que podem ser sociais, culturais, econômicas, espaciais, entre outras (SCHNEIDER, 2009).

Essa concepção é ancorada na teoria da ação definida por Bourdieu (1996), onde a reprodução socioeconômica ocorre por meio da adoção de estratégias, sendo estas definidas pela dinâmica social e pelas condições de sobrevivência dos indivíduos. Segundo o autor, as estratégias são estabelecidas de acordo com o habitus formalizado de cada indivíduo (BOURDIEU, 1996), construído a partir das experiências vivenciadas por este durante sua trajetória de socialização, desde seu relacionamento familiar até as suas relações de trabalho. Ou seja, são "todos os meios que, enfim, irão contribuir para a formação do indivíduo em determinado contexto social" (ALMEIDA, 2005, p. 142).

Desta forma, a formulação do habitus não só orienta práticas individuais dos indivíduos, mas também práticas coletivas (BOURDIEU, 2001). Isso se reflete nas 
estratégias de reprodução social do grupo familiar, que muitas vezes são produzidas separadamente (dadas às necessidades individuais de reprodução social de cada um) e que contribuem para as posições sociais adquiridas pela família em um contexto específico (BOURDIEU, 2001). Além disso, a família enquanto forma coletiva de organização e de trabalho é quem define a maior parte das estratégias de reprodução socioeconômica, dada pelo acumulo das relações e experiências sociais (BOURDIEU, 1996).

Assim, por meio do habitus é possível compreender como os agricultores familiares agem racionalmente por meio de práticas que possibilitam a reprodução e transformação das estruturas sociais onde estão inseridos (CASTRO, 2015). Os agricultores familiares são considerados atores sociais, "produtos da história, das lutas sociais e das experiências individuais acumuladas", ou seja, de um habitus socialmente construído (CASTRO, 2015, p. 101).

Ademais, o meio rural é caracterizado por uma heterogeneidade de formas e estilos de agricultura, composto por distintas estratégias de reprodução socioeconômica familiar, como a diversificação de atividades agrícolas, as atividades pluriativas, a produção para o autoconsumo, entre outros (SCHNEIDER, 2003). Assim, no caso deste estudo, enfatizam-se as agroindústrias rurais familiares como sendo uma dessas estratégias de reprodução utilizadas pelos agricultores, caracterizadas por práticas alimentares tradicionais, que preservam a cultura e os hábitos alimentares, formalizados pelo habitus socialmente construído, com atributos regionais e locais e que, ao mesmo tempo, agregam valor aos produtos da agricultura familiar, garantem renda as famílias e contribuem com a segurança alimentar e o desenvolvimento rural, por meio da disponibilização de produtos mais saudáveis, atentos aos aspectos sociais e ambientais.

\section{Agroindústrias Rurais Familiares (ARFs)}

Os avanços dos processos sociais, principalmente na agricultura caracterizada cada vez mais pelos mercados de commodities agrícolas - tem gerado uma série de preocupações no que se refere aos sistemas agroalimentares existentes. Entre essas preocupações estão os de garantir a segurança alimentar e a produção de alimentos mais sustentáveis, agroecológicos, orgânicos, entre outros (MATEI; SILVA, 2015).

Além disso, os estilos e modos de vida das pessoas também têm implicado em mudanças nos seus hábitos alimentares, na busca de alimentos mais saudáveis que garantam maiores níveis de saúde e qualidade de vida (SILVA; MARTINS, 2018). Desta forma, os consumidores têm valorizado produtos que possuem selo de origem e qualidade, produtos agroecológicos e orgânicos que são produzidos de forma artesanal e tradicional, com um número reduzido de processos de fabricação e com uma menor concentração de produtos químicos (SILVA; MARTINS, 2018).

Nesse sentido, a agricultura familiar desempenha papel fundamental no fornecimento de alimentos que atendem a esses padrões e hábitos dos consumidores e, ao mesmo tempo, estão engajados com as preocupações sociais, econômicas e ambientais (PREZOTTO, 2016). Além disso, a valorização da produção artesanal e tradicional dos produtos oriundos da agricultura familiar também contribui com o desenvolvimento das economias locais, pela inserção dos 
agricultores nos mercados, geração de renda familiar e preservação cultural, de hábitos e de costumes locais (PREZOTTO, 2016).

A agroindústria rural familiar (ARF) é uma das alternativas que os agricultores utilizam para expor seus produtos e se inserir em mercados cada vez mais competitivos. São espaços físicos definidos por um conjunto de

[...] atividades de transformação e beneficiamento de produtos agropecuários de origem animal ou vegetal, que são realizadas em instalações próprias, comunitárias ou de terceiros, a partir de matériaprima produzida no próprio estabelecimento agropecuário ou adquirida de outros produtores, desde que a destinação final do produto tivesse sido dada pelo produtor (IBGE, 2006, p. 62).

Desta forma, as ARFs vêm sendo incorporadas pelos agricultores como uma estratégia de reprodução socioeconômica na medida em que agrega valor aos produtos pelo processamento tradicional e artesanal, aumenta a autonomia da família em relação aos agentes externos e reduz intermediários ao longo da cadeia produtiva. Isso permite que o agricultor, além de processar, possa comercializar seus produtos diretamente com o consumidor, adquirindo maior rentabilidade (GNOATTO et al., 2004; MALUF, 2004).

Além disso, também contribui com a diversificação das atividades produtivas na propriedade, reduzindo os riscos relacionados à sazonalidade de receitas, o que garante maior estabilidade e segurança a unidade familiar em situações adversas, garantindo sua permanência no meio rural (AGNE; WAQUIL, 2011; WESZ JUNIOR; TRENTIN; FILLIPI, 2009).

Segundo Mior (2005, p. 8), as ARFs podem ser constituídas por uma única unidade familiar ou por um conjunto de famílias, que envolvem, além de suas características físicas, atributos culturais, experiências familiares, hábitos e costumes regionais, artesanais, sociais, ecológicos, etc., que caracterizam o habitus familiar de cada unidade produtiva (MIOR, 2005; BOURDIEU, 1996).

Assim, o processo de agroindustrialização é uma forma de desenvolvimento local e regional, uma vez que seus produtos são produzidos e processados dentro da unidade familiar e no contexto local (WESZ JUNIOR; TRENTIN; FILLIPI, 2009). Mais do que práticas mercantis, constituem a base de autonomia cultural e política dos agricultores familiares pela sua inserção no mercado e pela oferta de produtos mais saudáveis e agroecológicos de forma a atender as novas demandas dos consumidores, contribuindo com a segurança alimentar (NIERDERLE; WESZ JUNIOR, 2009).

A agroindustrialização como processo de organização familiar também oportuniza "a inclusão social, promovendo a participação e a equidade, especialmente de segmentos menos privilegiados como, por exemplo, as mulheres, os (as) idosos (as) e os (as) jovens" (PREZOTTO, 2016, p. 10). Sua importância como alternativa de renda complementar contribui com a permanência dos jovens no campo, promovendo a sucessão do grupo familiar (GAZOLLA; PELEGRINI, 2011; GOMES; SCHMIDT, 2014).

Segundo os estudos de Gazolla e Pelegrini (2011), o surgimento das agroindústrias conta com experiências e conhecimentos das famílias rurais em 61,32\% dos casos e o interesse dos agricultores rurais em propor uma nova atividade. 0 
desenvolvimento dessas práticas vem, ao longo do tempo, adequando e melhorando a forma de produzir, sendo esta uma alternativa de solução para os problemas enfrentados, como baixa produtividade, dificuldades econômicas, migração dos filhos para a cidade, entre outros (GAZOLLA; PELEGRINI, 2011).

Além disso, a industrialização de produtos agropecuários praticada na maioria das unidades familiares, mesmo que não comercializada, não é uma novidade e sim constituída de um habitus familiar que perpassa de gerações em gerações. Segundo Prezotto (2002), a transformação dos produtos já faz parte da história e cultura das famílias, que tinha como principal objetivo o consumo familiar, sendo que somente o excedente desta produção era comercializado em mercados locais. Exemplos desses produtos são citados pelo autor, como a elaboração de geleias a partir das frutas existentes na propriedade (uva, pêssego, laranja, morango...), de conservas e da fabricação de salames e queijos, entre outros (PREZOTTO, 2002).

Portanto, as ARFs são uma das diversas alternativas que os agricultores familiares utilizam como forma de reprodução socioeconômica no meio rural. São atividades que complementam a renda familiar, agregam valor aos seus produtos, diversificam as atividades desenvolvidas na propriedade, contribuem com a inserção dos agricultores nos mercados, auxiliam nos processos de sucessão familiar, melhoram os padrões de vida das famílias e ofertam produtos mais saudáveis, contribuindo com o desenvolvimento local.

\section{Procedimentos metodológicos}

Este estudo se utiliza de uma pesquisa de natureza básica que "objetiva gerar conhecimentos novos úteis para o avanço da ciência sem aplicação prática prevista" (PRODANOV; FREITAS, 2013, p. 51). Além disso, se classifica como uma pesquisa qualitativa como forma de abordagem do problema de estudo, muito utilizada no campo das ciências sociais, ao qual procura compreender e explicar o contexto e a dinâmica das relações sociais do objeto em estudo (RAMOS, 2009; GERHARDT; SILVEIRA, 2009).

Quanto aos objetivos, é classificada como uma pesquisa exploratória com a finalidade de levantar mais informações sobre o tema em estudo (PRODANOV; FREITAS, 2013). O procedimento técnico de levantamento dos dados se deu por meio de uma pesquisa bibliográfica de trabalhos científicos que discutem questões relacionadas a agroindústrias rurais familiares e as estratégias de reprodução socioeconômica no meio rural e por um estudo de caso. O estudo de caso é definido como um estudo aprofundado e detalhado de um ou poucos objetos considerando um contexto empírico da realidade (GIL, 2008).

No caso deste trabalho, o contexto empírico de pesquisa compreendeu quatro agroindústrias familiares da região noroeste do Rio Grande do Sul. Uma delas localiza-se no município de Campo Novo e as outras três no município de Santo Augusto. Os critérios de escolha destas foram pela localização próxima aos pesquisadores, por serem as únicas agroindústrias familiares destes municípios que são legalizadas ou estão em processo de legalização e por não haver estudos que enfatizam essas questões neste contexto empírico.

O procedimento de coleta dos dados deu-se por meio de entrevistas realizadas pelo pesquisador diretamente com os gestores das quatro agroindústrias 
pesquisadas, no período de dezembro de 2017. Assim foram utilizados questionários mistos (com questões abertas e fechadas) para a coleta de dados e informações. Como forma de preservar a identificação das quatro agroindústrias familiares pesquisadas, optou-se pela denominação algébrica das mesmas, sendo a agroindústria A, processadora de mandioca, agroindústria $\mathrm{B}$ de panificados, agroindústria $C$ de embutidos e agroindústria $D$ de melado.

O método de análise dos dados utilizado foi análise descritiva. Esta consiste em "organizar, resumir e descrever os aspectos importantes de um conjunto de características observadas ou comparar tais características entre dois ou mais conjuntos" (REIS, E. A.; REIS, I. A., 2002). As ferramentas de análise, nesse caso, envolvem a utilização de gráficos, tabelas, porcentagens, médias, entre outros, que permitem analisar as informações coletadas de forma dinâmica buscando caracterizar os aspectos principais do objeto em estudo.

\section{Resultados e Discussões}

Nesta seção, serão descritos os principais resultados encontrados por meio das entrevistas realizadas nas agroindústrias selecionadas no estudo de caso, definidas como: agroindústria A (processadora de melado), agroindústria B (de embutidos), agroindústria $C$ (de mandioca) e agroindústria $D$ (de panificados). Nesse sentido, procura-se caracterizar as agroindústrias familiares, o perfil dos gestores, os principais produtos processados e canais de comercialização utilizados pelas mesmas. Por fim, são apresentadas algumas dificuldades e desafios relatados pelos gestores na manutenção de suas agroindústrias.

\subsection{Caracterização das Agroindústrias Familiares}

As quatro agroindústrias familiares pesquisadas possuem basicamente mão de obra familiar em que todos os membros estão de algum modo associados às tarefas, principalmente seus gestores. Estes afirmaram participar de todo o processo produtivo - desde a obtenção ou plantio da matéria-prima até a comercialização do produto acabado.

A agroindústria familiar, em todos os casos, é a principal atividade desenvolvida na propriedade e fonte de renda dos agricultores. Três dos proprietários entrevistados também associam a agroindústria com a produção agropecuária, atividades da qual extraem, inclusive, sua matéria-prima. Além disso, essas atividades já faziam parte da propriedade antes da implementação da agroindústria.

O surgimento de duas das agroindústrias familiares se deu em virtude de incentivos locais, sobretudo, pela Empresa de Assistência Técnica e Extensão Rural do município (EMATER) e pela Prefeitura Municipal. Nos outros casos, a agroindústria surgiu de uma necessidade de complementar a renda familiar, uma vez que as atividades antes desenvolvidas na propriedade não estavam sendo suficientes para garantir a renda familiar, bem como, pela exigência dos mercados e pela tradição e experiência no ramo, o que enfatiza o habitus familiar (Quadro 1). 
Quadro 1. Atividades desenvolvidas na propriedade dos entrevistados e os motivos do surgimento da agroindústria - dezembro de 2017

\begin{tabular}{|c|c|c|}
\hline AGROINDÚSTRIA & ATIVIDADES ANTERIORES & ORIGEM DA AGROINDÚSTRIA \\
\hline A & $\begin{array}{c}\text { Pecuária Leiteira e } \\
\text { Produção de Grãos }\end{array}$ & Necessidade de complementar a renda da família \\
\hline B & Suinocultura & Tradição Familiar \\
\hline C & Produção de Hortaliças e \\
Grãos & $\begin{array}{c}\text { Incentivo das instituições locais (Emater e } \\
\text { prefeitura) e pela exigência dos mercados }\end{array}$ \\
\hline D & Pecuária Leiteira & $\begin{array}{r}\text { Incentivo das instituições locais (Emater e } \\
\text { prefeitura) e pela necessidade de complementar } \\
\text { a renda }\end{array}$ \\
\hline
\end{tabular}

Fonte: Pesquisa a campo, 2017.

Em relação à formalidade das agroindústrias, somente uma ainda não está trabalhando de forma legalizada, mas a documentação já foi encaminhada para a aquisição do selo "Sabor Gaúcho". O selo de certificação "Sabor Gaúcho" permite que os produtos sejam identificados nos supermercados, feiras e pontos de vendas como sendo oriundos de agroindústrias familiares rurais gaúchas. Estes produtos são caracterizados por serem produzidos artesanalmente, aliados ao desenvolvimento sustentável, geração de emprego e renda no campo e preservação do meio ambiente. Todas as agroindústrias que detêm este selo participam do Programa Estadual de Agroindústria Familiar (PEAF) (SECRETARIA DE DESENVOLVIMENTO RURAL PESCA E COOPERATIVISMO/RS - SDR, 2017).

Todos os entrevistados afirmaram estar satisfeitos com a lucratividade da agroindústria e esperam obter maiores rendimentos em um futuro próximo. As receitas e o lucro líquido mensal estimado em duas das agroindústrias pesquisadas variam de dois a cinco salários mínimos e, para as outras duas, o rendimento é maior do que seis salários mínimos. Com a maior lucratividade obtida, acreditam na permanência dos filhos, nas duas propriedades que possuem sucessão, para continuar no meio rural e seguir com as atividades que estão sendo realizadas na agroindústria.

\subsection{Perfil dos Gestores}

Em relação ao perfil das famílias responsáveis pelas agroindústrias, verificouse que estas são compostas de dois a três membros. Em duas das agroindústrias (A e C) as atividades são geridas pelo casal e pelo filho, fato que não pode ser observado nas outras duas agroindústrias ( $B$ e $D$ ), onde as atividades são gerenciadas somente pelo casal, que apresentam idades entre 40 e 57 anos (Quadro 2).

Quadro 2. Perfil das famílias responsáveis pelas atividades da agroindústria dezembro de 2017

\begin{tabular}{|c|c|c|c|}
\hline Agroindústria & Composição familiar & Idade & Escolaridade \\
\hline A & Três pessoas & Homem/pai: 55 anos & Fundamental incompleto \\
\hline
\end{tabular}




\begin{tabular}{|c|c|c|c|}
\hline \multirow{2}{*}{ B } & \multirow{2}{*}{} & Mulher/mãe: 44 anos & Superior completo \\
\cline { 3 - 4 } & \multirow{2}{*}{ Duas pessoas } & Homem/pai: 42 anos & Médio completo \\
\cline { 3 - 4 } & \multirow{3}{*}{ C } & Mulher/mãe: 40 anos & \\
\hline \multirow{2}{*}{ Crês pessoas } & Homem/pai: 46 anos & Fundamental incompleto \\
\cline { 3 - 4 } & \multirow{2}{*}{ D } & Mulher/mãe: 45 anos & Médio incompleto \\
\cline { 3 - 4 } & \multirow{2}{*}{ Duas pessoas } & Filho: 24 anos & Médio completo \\
\cline { 3 - 4 } & & Homem/pai: 51 anos & Fundamental incompleto \\
\hline
\end{tabular}

Fonte: Pesquisa a campo, 2017.

Com relação ao grau de escolaridade dos entrevistados, esse varia do ensino fundamental incompleto ao ensino superior completo. Os maiores níveis de escolaridade são representados pelos dois jovens que possuem idade de 24 e 25 anos, bem como, pelo casal da agroindústria B. Desta forma, em duas das agroindústrias pesquisadas, a sucessão familiar não preocupa os entrevistados, onde filhos jovens são os principais responsáveis pela produção e recebem apenas auxílio dos pais no momento do processamento.

Segundo Gomes e Schmidt (2014), o número de jovens no campo vem diminuindo significativamente, pois saem rumo às cidades em busca de trabalho. Para que os jovens permaneçam, há necessidade de procurar formas que estimulem a sua escolha em permanecer no campo. Assim, as agroindústrias familiares têm sido uma das alternativas, permitindo a geração de renda, qualidade de vida no meio rural e uma melhor relação social entre as famílias, através do processamento da matériaprima da própria propriedade (GOMES; SCHMIDT, 2014; ORSOLIN, 2006).

\subsection{Tipos de produtos e canais de comercialização}

Os produtos comercializados pelas agroindústrias são basicamente os alimentícios de origem animal ou vegetal, como melado, embutidos (salames), mandioca e panificados. Entretanto, apenas uma das agroindústrias produz sua própria matéria-prima, já as outras adquirem matéria-prima total ou parcial de lugares externos a propriedade, como no caso da agroindústria $B$ (de embutidos) que compra $100 \%$ de sua matéria prima (carne) de outro munícipio e a agroindústria D (de panificados) que compra cerca de $70 \%$ a $80 \%$ de farinha e outros subprodutos para o processamento no supermercado (Quadro 3).

Quanto aos canais de comercialização das agroindústrias familiares pesquisadas, percebe-se uma diversificação de segmentos, ou seja, cada agroindústria possui mais de um canal em que comercializa seus produtos, como feiras, vendas a domicílio, supermercados e escolas, entre outros, todos locais (Quadro 3). Segundo Hahn et al. (2017), a diversificação dos canais de comercialização é um ponto positivo em relação às agroindústrias familiares. Isso mostra a autonomia dos agricultores para se relacionar e escolher o melhor mercado, pois, se seus produtos não se enquadrarem em um dos mercados, haverá outros para se proteger em épocas de crises (HAHN et al., 2017). 
Quadro 3. Principais características de produtos e de comercialização das agroindústrias familiares - dezembro de 2017

\begin{tabular}{|c|c|c|c|c|}
\hline $\begin{array}{c}\text { Agroindústrias } \\
\text { Familiares }\end{array}$ & A & B & C & D \\
\hline Origem do Segmento & Vegetal & Animal & Vegetal & Vegetal \\
\hline $\begin{array}{c}\text { Tipo de Produto } \\
\text { Origem da Matéria- } \\
\text { prima }\end{array}$ & Melado & Embutidos & Mandioca & Panificados \\
\hline $\begin{array}{c}\text { Local de } \\
\text { Comercialização }\end{array}$ & $\begin{array}{c}\text { Venda domicílio, } \\
\text { supermercado e } \\
\text { para feirantes }\end{array}$ & $\begin{array}{c}\text { Supermercados, } \\
\text { restaurantes e } \\
\text { padarias }\end{array}$ & $\begin{array}{c}\text { Supermercados e } \\
\text { venda a domicílio }\end{array}$ & $\begin{array}{c}\text { Domicílio, feiras } \\
\text { e escolas }\end{array}$ \\
\hline $\begin{array}{c}\text { Frequência } \\
\text { comercialização }\end{array}$ & 2 dias por semana $80 \%$ \\
\hline
\end{tabular}

Fonte: Pesquisa a campo, 2017.

Dentre os principais canais de comercialização estão os supermercados, onde três das agroindústrias mais comercializam sua produção, entre 50\%, 80\% e 90\%, respectivamente (Tabela 1). Já a agroindústria $D$ (de panificados) comercializa maior quantidade (60\% do total) de seus produtos em escolas pelo Programa Nacional de Alimentação Escolar (PNAE).

Tabela 1. Níveis de comercialização das agroindústrias familiares em cada segmento de mercado (\%) - dezembro de 2017

\begin{tabular}{lcccc}
\hline \multirow{2}{*}{ Segmentos } & \multicolumn{4}{c}{ Percentual de comercialização } \\
\cline { 2 - 5 } & A & B & C & D \\
Supermercados & $50 \%$ & $80 \%$ & $90 \%$ & - \\
Feiras & - & - & - & $35 \%$ \\
Alimentação & - & - & - & $60 \%$ \\
escolar & $40 \%$ & $12 \%$ & $10 \%$ & $5 \%$ \\
Domicílio & $10 \%$ & $8 \%$ & - & - \\
\hline Outros & $100 \%$ & $100 \%$ & $100 \%$ & $100 \%$ \\
\hline Total & & & \\
\hline
\end{tabular}

Fonte: Pesquisa a campo, 2017.

Além disso, quando questionados sobre as principais características que permitem diferenciar os produtos que são processados em suas agroindústrias, as opções mais marcadas pelos entrevistados foram à qualidade, o sabor e a aparência dos produtos, pois os mesmos são produzidos de forma tradicional, sem a adição de produtos químicos, que garantem os seus atributos naturais.

\subsection{Dificuldades e desafios dos gestores das agroindústrias}


O meio rural vem enfrentando transformações demográficas nos últimos anos, evidenciadas principalmente a partir dos anos de 1970 e 1980 com o êxodo rural. Segundo Cintra e Bazotti (2012), essas transformações são caracterizadas pela passagem de uma população rural mais numerosa e jovem para uma população mais envelhecida e pequena, que pode ser observada desde a configuração das famílias, que apresentavam em média de cinco membros nesse período para famílias com média de três membros atualmente (DALBIANCO et al., 2009; CINTRA; BAZOTTI, 2012).

A redução da configuração das famílias também pode ser observada nas propriedades das agroindústrias pesquisadas. $\mathrm{Em}$ duas das agroindústrias (agroindústria $\mathrm{A}$ e $\mathrm{C}$ ) as famílias são compostas de três membros (casal e filho), tendo relatado não haver problemas com a sucessão em um futuro próximo, de forma a continuar com as atividades desenvolvidas na agroindústria. Esse fato já não pode ser observado nas outras duas agroindústrias ( $B$ e $D$ ), onde a família que gerencia as atividades é composta somente por duas pessoas (casal).

Assim, uma das dificuldades encontradas pelos gestores dessas duas últimas agroindústrias está na questão de dar sequência às atividades das mesmas, bem como, relatam também a dificuldade de aumentar a capacidade produtiva, pela falta de mão de obra, principalmente qualificada e, no caso da agroindústria $D$, da saúde de um dos gestores. Esses fatores podem acabar limitando a reprodução socioeconômica dessas unidades familiares no futuro, pois sem a sucessão e com idade mais avançada os gestores acabam desistindo das atividades e encontrando outras estratégias de fonte de renda como o arrendamento da terra, a migração para a cidade, por exemplo (DALBIANCO et al., 2009; BURATTI et al., 2018).

Outras dificuldades relatadas pelos entrevistados são o valor elevado e a pouca disponibilidade da matéria-prima, evidenciadas principalmente em duas das agroindústrias familiares (de embutidos e panificados), onde em média $80 \%$ desse recurso é comprado, dada a falta de mão de obra para o processo produtivo e de especialização em certos produtos (farinhas, temperos, fermentos, entre outros). Esse fato é observado por Dalbianco et al. (2009) em estudo acerca das agroindústrias familiares do município de Santa Rosa (RS), realizado em outubro de 2008, onde alguns dos agricultores não têm a capacidade produtiva, mão de obra e especialização suficientes para produzir sua própria matéria-prima na propriedade, tendo de compra-la no mercado (DALBIANCO et al., 2009).

Dalbianco et al. (2009) ressaltam a importância dos agricultores produzirem sua própria matéria-prima. Segundo os autores, a produção de matéria-prima na propriedade aumenta a autonomia dos agricultores frente aos mercados, permitindo a estes ter maior segurança do negócio, reduzindo custos de produção pela agroindústria e garantindo maior qualidade aos produtos, na medida em que preservam os atributos naturais da matéria-prima, produzida de forma tradicional (DALBIANCO et al., 2009).

\section{Considerações Finais}

Este estudo buscou analisar a importância dos processos de agroindustrialização como estratégia de reprodução socioeconômica da agricultura familiar e do desenvolvimento de economias locais, enfatizando a importância dessa 
categoria social como produtora de alimentos. Pode-se concluir pelos resultados apresentados que as agroindústrias rurais familiares são utilizadas pelos agricultores como uma estratégia de reprodução socioeconômica, principalmente, quanto à complementação da renda, a diversificação produtiva e a agregação de valor aos seus produtos, uma vez que somente as rendas das atividades antes desenvolvidas acabavam não sendo suficientes para o sustento da família.

Além disso, pode-se observar através dos resultados, a importância dos órgãos públicos locais em incentivar os processos de agroindustrialização nas propriedades rurais, como forma de promover o desenvolvimento dos mercados locais, gerar renda e emprego. Esses incentivos contribuem para que os agricultores se envolvam nessas atividades, garantindo sua permanência no campo, principalmente dos jovens. Além disso, as agroindústrias também são caracterizadas pela tradição familiar, evidenciando o habitus de cada agricultor, que já realizavam o processamento dos produtos na propriedade para o autoconsumo da família.

Os resultados também demostraram que os agricultores utilizam diferentes formas de comercialização da produção, como feiras, supermercados, vendas a domicílio, PNAE e restaurantes. Essa estratégia garante aos agricultores maior segurança na comercialização de seus produtos, garantindo a sua venda, pois se algum dos canais de comercialização não receber o produto, os agricultores podem se utilizar dos outros canais.

Entretanto, a nova configuração do rural e a migração da população do campo também afeta as agroindústrias familiares, principalmente pela falta de mão de obra qualificada em casos de picos de produção, pela falta de sucessão familiar e pela forma reduzida ao qual se encontram as famílias que ainda residem no rural atualmente. Essas limitações acabam afetando a reprodução socioeconômica familiar dos agricultores que passam a utilizar outras formas de garantir renda, como os arrendamentos da terra e as migrações para a cidade.

Desta forma, torna-se importante a promoção de políticas públicas, programas e projetos locais tanto em âmbito social, econômico e/ou produtivo, de incentivo aos agricultores, principalmente os jovens, a permanecer no campo e desenvolver atividades que valorizem o meio rural. As agroindústrias familiares são uma dessas alternativas que devem ser incentivadas, pois além de contribuir com o desenvolvimento rural, também contribuem com os novos padrões de consumo dos sistemas agroalimentares, alinhados as questões sociais, econômicas e ambientais.

\section{REFERÊNCIAS}

AGNE, C. L.; WAQUIL, P. D. Redes de proximidade: agricultores, instituições e consumidores na construção social dos mercados para os produtos das agroindústrias rurais familiares na região central do RS. REDES. Santa Cruz do Sul, v.16, n.1, p.149-171, jan./abr. 2011. Disponível em: <https://online.unisc.br/seer/index.php/redes/article/view/1609>. Acesso em: 17 dez. 2017. DOI: http://dx.doi10.17058/redes.v16i1.1609. 
ALMEIDA, L. R. da S. Pierre Bourdieu: a transformação social no contexto de "a reprodução". Inter-Ação, Faculdade de Educação da UFG, v.30, n.1, 139-155, jan./jun. 2005. Disponível em: < https://www.revistas.ufg.br/interacao/article/view/1291/1343 >. Acesso em: 08 mai. 2019.

BORTOLUZZI, D. L. Agroindústria familiar rural e desenvolvimento econômico: um estudo no Município de Doutor Maurício Cardoso/RS. Trabalho de Conclusão de Curso em Ciências Econômicas (TCC), Curso de Ciências Econômicas, Faculdade de Horizontina. 2013. 91f.

BOURDIEU, P. Meditações Pascalianas. Rio de Janeiro: Bertrand Brasil, 2001. 324 p.

. Razões práticas: sobre a teoria da ação. Campinas: Papirus, 1996. 224 p.

CASTRO, L. F. P. de. Agricultura familiar, habitus e acesso a terra. Revista Brasileira de Sociologia do Direito, v. 2, n. 2, p. 91-105, mai./ago., 2015. DOI:

http://dx.doi.org/10.21910/rbsd.v2n2.2015.17

CINTRA, A. P. de U.; BAZOTTI, A. População rural, agricultura familiar e transmissão do saber na Região Sul. Caderno IPARDES, Curitiba, v. 2, n. 1, p. 80-94, jan./jun. 2012.

DALBIANCO, V. P. et al. Limites e potencialidades das agroindústrias familiares: 0 caso do município de Santa Rosa, RS. Apresentação Oral: Instituições e Desenvolvimento Social na Agricultura e Agroindústria, SOBER, Porto Alegre, 26 a 30 de julho de 2009. Disponível em: <http://www.sob

http://www.sober.org.br/palestra/13/1082.er.org.br/palestra/13/1082>. Acesso em: 10 mai. 2019.

EMPRESA DE ASSISTÊNCIA TÉCNICA E EXTENSÃO RURAL DO GOVERNO DO RIO GRANDE DO SUL - EMATER/RS. Agroindústria Familiar. Porto Alegre, 2009. Disponível em: <http://www.emater.tche.br/site/area-tecnica/agregacao-devalor/agroindustria-familiar.php\#.XNIffhRKjIU>. Acesso em: 09 mai. 2019.

FERNANDES, D. M. M.; ENGEL, B. S. Agroindústrias familiares rurais: vantagens e desvantagens da legalização. Redes, Santa Cruz do Sul, v. 21, n. 3, p.183-214, set./dez. 2016. Disponível em:

<https://online.unisc.br/seer/index.php/redes/article/view/6904>. Acesso em: 17 dez. 2017. DOI: 10.17058/redes.v21i3.6904.

GAZOLLA, Marcio; PELEGRINI, G. A agroindústria familiar: uma estratégia de agregação de valor a produção e renda das famílias rurais. Apresentação OralAgricultura Familiar e Ruralidade, 2008.

GAZOLLA, M.; PELEGRINI, M. As experiências familiares de agroindustrialização: uma estratégia de produção de novidades e de valor agregado. Ensaios FEE, v.32, n.2, p.361-388, Porto Alegre, nov. 2011. 
GERHARDT, T. E. ; SILVEIRA, D. T. (Org.). Métodos de pesquisa. 1. Ed. Porto Alegre: UFRGS, 2009. $120 \mathrm{p}$.

GIL, A. C. Métodos e técnicas de pesquisa social. 6. Ed. São Paulo: Atlas, 2008.

GNOATTO, A. A. et al. Pluriatividade, agroindústria e agricultura familiar. In: XLII Congresso da Sociedade Brasileira de Economia e Sociologia Rural. Anais... Cuiabá, Mato Grosso, v.1, 2004. Disponível em:<www.sober.org.br/palestra/12/ogP445.pdf>. Acesso em: 05 mai. 2019.

GOMES, E. J. ; SCHMIDT, C. E. F. A Importância das Redes Cooperativas de Agroindústrias Familiares para a Permanência dos Jovens no Meio Rural. Reflexão Cooperativista, n.3, p.77-82, Porto Alegre, ago. 2014. Disponível em: <http://escoop.edu.br/wp-content/uploads/2017/05/miolo_reflexao_impressao.pdf>. Acesso em: 06 dez. 2017.

HAHN, C. L. et al. Análise de mercado dos produtos da agroindústria familiar: Estudo de caso do perfil do consumidor e do produtor Santo-Angelense - Rio Grande do Sul - Brasil. Espacios, v.38, n.21, p.5, Caracas, 2017. Disponível em: <http://www.revistaespacios.com/a17v38n21/a17v38n21p05.pdf >. Acesso em: 17 dez. 2017.

INSTITUTO BRASILEIRO DE GEOGRAFIA E ESTATÍSTICA (IBGE). Censo Agropecuário 2006: Brasil, grandes regiões e unidades da federação. Rio de Janeiro: IBGE, 2006. p.1-777. Disponível em: <http://www.ibge.gov.br/home/estatistica/economia/agropecuaria/censoagro/brasil _2006/Brasil_censoagro2006.pdf>. Acesso em: 16 out. 2017.

JEAN, B. A forma social da agricultura familiar contemporânea: sobrevivência ou criação da economia moderna. Cadernos de Sociologia, v. 6, p. 51-75, Porto Alegre, 1994.

MALUF, R. S. Mercados agroalimentares e a agricultura familiar no Brasil: agregação de valor, cadeias integradas e circuitos regionais. Ensaios FEE, v.25, n.1, p.299-322, Porto Alegre, abr. 2004.

MATEI, A. P.; SILVA, L. X. da. Inovação, Agroindústrias Familiares e Sistemas Agroalimentares Locais na Serra Gaúcha. Revista IDeAS, v. 9, n. 2, p. 8-44, 2015.

MIOR, L. C. Agricultores familiares, agroindústrias e redes de desenvolvimento rural. Chapecó: Argos, 2005.

NIEDERLE, P. A.; ESCHER, F.; CONDERATO, M. Estilos de agricultura: capturando a diversidade do rural contemporâneo. In: CONDERATO, M.; RADOMSKY, G. F. W; SCHNEIDER, S. (Orgs.) Pesquisa em desenvolvimento rural: aportes teóricos e proposições metodológicas. Vol.1. Porto Alegre: UFRGS Editora, 2014. p. 205-225. 
NIEDERLE, P. A.; WESZ JUNIOR, V. J. A agroindústria familiar na região Missões: construção de autonomia e diversificação dos meios de vida. REDES, Santa Cruz do Sul, v. 14, n. 3, p.75-102, set./dez. 2009. DOI: http://dx.doi.org/10.17058/redes.v14i3.566

ORSOLIN, J. Gestão da comercialização na Agroindústria Rural Familiar. Revista de Administração, v.5, n.8, p.15-37, Frederico Westphalen, jun. 2006. Disponível em: <www.revistas.fw.uri.br/index.php/revistadeadm/article/download/800/1346>. Acesso em: 17 dez. 2017.

PLEIN, C. As metamorfoses da agricultura familiar: o caso do município de Iporã d'Oeste, Santa Catarina. Dissertação, Curso de Pós-Graduação em Desenvolvimento Rural da Faculdade de Ciências Econômicas, Universidade Federal do Rio Grande do Sul, 2003. 156f. Disponível em: <https://www.lume.ufrgs.br/handle/10183/2666>. Acesso em: 08 mai. 2019.

PLEIN, C. A modernização da agricultura brasileira e seus efeitos sobre a agricultura familiar no oeste catarinense. Revista Faz Ciência, v.8, n.1, p.35-72. Universidade Estadual do Oeste do Paraná - UNIOESTE, 2006.

PLEIN, C. Capitalismo, agricultura familiar e mercantilização. Informe GEPEC, Toledo, v. 14, n. 2, p. 96-111, jul./dez. 2010. Disponível em: < file:///C:/Users/Usu\%C3\%A1rio/Downloads/4008-18494-1-PB.pdf>. Acesso em: 27 out. 2018.

PLOEG, J. D. van der. El proceso de trabajo agrícola y la mercantilización. In: GUZMÁN, E. S. (Ed.). Ecología, campesinado y historia. España: Lãs Ediciones de la Piqueta, 1992.

PREZOTTO, L. L. Uma concepção de agroindústria rural de pequeno porte. Revista de Ciências Humanas, Florianópolis, EDUFSC, n. 31, p. 133-153, 2002. Disponível em: < https://periodicos.ufsc.br/index.php/revistacfh/article/viewFile/25195/22152>. Acesso em: 25 jun. 2019.

PREZZOTO, L. L. Agroindústria da agricultura familiar: regularização e acesso ao mercado. Brasília: CONTAG, 2016.60 p.

PRODANOV, C. C; FREITAS, E. C. de. Metodologia do trabalho científico: métodos e técnicas da pesquisa e do trabalho acadêmico. 2. Ed. Novo Hamburgo: Feevale, 2013.

RAMOS, A. Metodologia da pesquisa científica: como uma monografia pode abrir o horizonte do conhecimento. São Paulo: Atlas, 2009. 
REIS, E. A.; REIS I. A. Análise Descritiva de Dados. Relatório Técnico, Departamento de Estatística, Universidade Federal de Minas Gerais, Instituto de Ciências Exatas. Ed. 1, 2002.

SECRETARIA ESTADUAL DE DESENVOLVIMENTO RURAL, PESCA E COOPERATIVISMO/RS (SDR). Manual de identidade visual Sabor Gaúcho. Porto Alegre, 2017. Disponível em: <www.sdr.rs.gov.br/programa-estadual-de-agriculturafamiliar>. Acesso em: 20 dez. 2017.

SECRETARIA ESTADUAL DO DESENVOLVIMENTO RURAL, PESCA E COOPERATIVISMO (SDR). Relação de Agroindústrias Inclusas no Programa Estadual de Agroindústria Familiar (PEAF). Departamento de Agricultura Familiar e a Agroindústria (DACA). Porto Alegre, Out. 2018. Disponível em: <https://www.sdr.rs.gov.br/programa-estadual-de-agricultura-familiar>. Acesso em: 07 mai. 2019.

SCHNEIDER, S. Teoria social, agricultura familiar e pluriatividade. Revista Brasileira de Ciências Sociais, v.18, n.51, p.99-121, fev. 2003. Disponível em: < http://www.scielo.br/pdf/rbcsoc/v18n51/15988>. Acesso em: 07 mai. 2019.

. A pluriatividade na agricultura familiar. 2. Ed. Porto Alegre: Editora da UFRGS, 2009.

SCHNEIDER, S.; NIEDERLE, P. Resistance strategies and diversification of rural livelihoods: the construction of autonomy among Brazilian family farmers. Journal of Peasant Studies, 2010, 37 (2), pp. 379-405. Disponível em:

<https://doi.org/10.1080/03066151003595168>. Acesso em: 15 nov. 2018.

SILVA, J. M.; HESPANHOL, R. A. DE M. As estratégias de reprodução social dos agricultores familiares das comunidades rurais do município de Catalão (GO). Geo UERJ, Rio de Janeiro, n. 29, p. 402-430, 2016. DOI:10.12957/geouerj.2016.20304

SILVA, C. A. da; MARTINS, G. A. de S. Alimentos Funcionais: tecnologia aliada a saúde. Revista Desafios, Tocantins, v. 5, n. 3, 2018. https://doi.org/10.20873/uft.23593652.2018v5n3p1

STRATE, M. F. D.; CONTERATO, M. A. Práticas de agroindustrialização e arranjos produtivos locais como estratégia de diversificar e fortalecer a agricultura familiar no Rio Grande do Sul. Redes (Santa Cruz do Sul. Online), v. 24, n. 1, p. 227 - 245, janeiro-abril, 2019. DOI: 10.17058/redes.v2411.13052

WANDERLEY, M. de N. B. A valorização da agricultura familiar e a reivindicação da ruralidade no Brasil. Desenvolvimento e Meio Ambiente, n. 2, p 29-37, jul./dez., 2000. DOI: http://dx.doi.org/10.5380/dma.v2io.22105

. O Campesinato Brasileiro: uma história de resistência. Revista de Economia e Sociologia Rural (RESR), v.52, S.1, p. So25-S044, Piracicaba, São Paulo, 2014. 
Disponível em: < http://www.scielo.br/pdf/resr/v52s1/a02v52s1.pdf >. Acesso em: 07 mai. 2019.

WESZ JUNIOR, V. J.; TRENTIN, I. C. L.; FILIPPI, E. E. Os reflexos das agroindústrias familiares para o desenvolvimento das áreas rurais no Sul do Brasil. Cuadernos de Desarrollo Rural, v.6, n.63, p.59-85, Bogotá, 2009.

Rosani Marisa Spanevello. Doutora em Desenvolvimento Rural pela UFRGS, mestre em Extensão Rural pela UFSM e graduada em Agronomia pela UFSM. Professora do curso de Zootecnia e do programa de pós-graduação em Agronegócios, UFSM, campus Palmeira das Missões. rspanevello@yahoo.com.br

Luana Cristina Duarte. Tecnóloga em Agronegócio pelo Instituto Federal Farroupilha Campus Santo Augusto, especialista em Espaços Alternativos do Ensino e Aprendizagem pelo Instituto Federal Farroupilha Campus Santo Augusto, mestranda em Agronegócios (UFSM), campus Palmeira das Missões.. luanacrisduarte@hotmail.com

Catia Letícia Corrêa Schneider. Graduada em Medicina Veterinária pela Universidade Federal de Santa Maria (UFSM), mestranda do programa de pósgraduação em Agronegócios da Universidade Federal de Santa Maria (UFSM), campus Palmeira das Missões. catiaschneidervet@gmail.com

Sinara Pizzi Martins. Bacharel em Ciências Econômicas pela Universidade Federal de Santa Maria (UFSM), Licenciada em Matemática - UNINTER, mestranda do programa de pós-graduação em Agronegócios da Universidade Federal de Santa Maria (UFSM), campus Palmeira das Missões. sinarapizzimartins@gmail.com

Como citar: SPANEVELLO, Rosani Marisa et al. Agroindústrias rurais familiares (ARFs) como estratégia de reprodução socioeconômica da agricultura familiar nos municípios de Santo Augusto e Campo Novo - RS. Redes, Santa Cruz do Sul, v. 24, n. 3, p. 198-216, set. 2019. ISSN 1982-6745. Disponível em: https://doi.org/10.17058/redes.v24i3.14125. 